\title{
Preliminary survey on endoparasitism in Ophiophagus hannah (Reptilia: Serpentes: Elapidae) in Mizoram, India
}

\author{
Lalbiakzuala, Lalrinsanga, Michael Vanlalchhuana, H.T. Lalremsanga* \\ Department of Zoology, Mizoram University, Tanhril 796004, Mizoram, India \\ Corresponding author: htlrsa@yahoo.co.in
}

\begin{abstract}
There is no record on the prevalence of parasites of snakes in Mizoram. This study was undertaken in an attempt to identify common gastrointestinal parasites in the king cobra Ophiophagus hannah In this preliminary survey, necropsy was performed on four individuals collected from different localities within Mizoram during January 2015 to June 2016. Of the 4 snakes examined, 1 was found infected with cestode, nematode and acanthocephalan. The Capillaria sp. and Kalicephalus sp. collected from $\mathbf{O}$. hannah in the present study was morphologically identified but molecular identification could not be done due to insufficient specimen. Acanthocephalan cystacanths were collected from the intestinal lining and were morphologically identified as belonging to the family Giganthorhynchidae. Metacestode of Taenia sp. was collected from the body cavity and was morphologically identified while molecular characterization could not be done as only a single specimen was collected. Accurate identification is very important in understanding the geographical distribution and biodiversity of parasites. However, the identification of parasites to the species level based solely on morphological analysis might be risky.
\end{abstract}

Keywords: Ophiophagus hannah, cestode, nematode, parasite, Mizoram.

\section{INTRODUCTION}

The class Reptilia is composed of four extant orders, namely Chelonia (tortoises and turtles), Crocodilia (alligators, caimans, crocodiles, gharial), Rhynchocephalia (tuataras), and Squamata (lizards, worm lizards, and snakes). The first known reptiles appeared during the Paleozoic era, about 300 million years ago (Jacobson, 2007). During the Mesozoic, often called the Age of Reptiles, there were 17 orders. Thus, reptiles are far less diverse now. The exact phylogenetic relationship among chelonians, crocodilians, and squamata is not resolved. Particularly, the relationship between chelonians and the reptile clade Diapsida (crocodilians, lizards, and snakes) remains contoversial (Jacobson, 2007). For example, molecular analyses indicate a relationship between chelonians and crocodilians (Zardoya and Meyer, 1998; Hedges and Poling, 1999), while osteological data indicate turtles within the diapsids as a sister group of the Sauopterygia, a group of Mesozoic reptiles (Rieppel and Reisz, 1999).
Ophidia (Serpentes) is the most recent group (order) of the present-day reptiles. The snake body is noticeably supple, capable of twisting and other movements that are impossible for other vertebrates. The structure of the backbone restricts any space for vertical movements, so that it is impossible for snakes to perform vertical undulatory movements. Thus, snakes move sideways (Daniel, 2002). Snakes are highly diverse and can be classified into 14 to 17 families. For instance, boas and pythons are sometimes placed in the family Boidae, while some authors separate them to Boidae and Pythonidae respectively (Jacobson, 2007). 3567 species of snakes have been recorded (Uetz, 2016), with 297 species India (Anon., 2014). In Mizoram 52 species of snakes have been reported by Lalremsanga and Lalronunga (2017). Lalbiakzuala and Lalremsanga (2017) made the first report of Lycodon fasciatus (banded wolf snake) from the state.

There is little information on parasitic infection in wild reptiles, particularly snakes. It is important to understand the degree and types of infection for wild life con- 
servation. Some helminths can be directly dangerous and even lethal, while some can be mildly pathogenic (Noryoska and Sokół, 2015). This study shows helminth infection in the king cobra, which is perhaps the first study in Mizoram.

\section{MATERIALS AND METHODS}

For cestodes, freshly recovered parasites were stretched in warm water and gently flattened between a slide and a cover glass and was fixed in 70\% ethyl alcohol. The specimen was stained with borax carmine, and dehydrated through ascending grades of ethyl alcohol, then cleared in methyl benzoate and mounted with DPX.

For nematodes, the worms were stretched in warm $70 \%$ alcohol. For permanent mounting, the worms were cleared in ascending grades of glycerine and finally double mounted using Kaiser's glycerine jelly $(50 \mathrm{~mL}$ water + 80 gm gelatin $+50 \mathrm{~mL}$ glycerol +0.1 gm phenol); for temporary mounting, the specimen were immersed in lactophenol overnight and temporarily mount with the same solution on the glass slide.

For Acanthocaephala, the parasites were allowed to relax in hot saline and narcotized by adding a few drops of $70 \%$ alcohol and further processed following usual procedure of flattening and permanent mounting.

Generic identification of the parasites was done following standard reference works (Yamaguti, 1959a, 1959b, 1961, 1971; CIH Keys to Nematodes 1-10; Khalil et al., 1994).

\section{RESULTS}

During the study period, i.e. 2016-2017, O. hannah caught from the wild were immediately kept in a terrarium. Road killed specimen were also collected and kept immediately in a cold storage. A total of 4 individuals were examined and and found positive with helminth parasitic infection viz. Taenia sp., Capillaria sp., Ophidascaris sp. and Acanthocephala.

\section{DISCUSSION}

Endoparasites of vertebrates are representatives of two phyla - the acoelomate Platyhelminthes and the pseudocoelornate Nematoda. Parasitic infections are often chronic and in optimal habitat and maintenance conditions do not give clear clinical symptoms. Stress of transport, inadequate microclimate in the terraria, concentration of animals or improper nutrition, can suppress the immune system and lead to clinical form of parasitic diseases. But not all parasites are harmful to the reptile host; those that just pass through the intestinal tract are usually not (Schneller and Pantchev, 2008).

Plasmodium infections are suggested to cause changes in behavior and physiology of certain popula- tions of lizards (Schall, 1996); the coccidian Caryospora was responsible for mortality in captive (Leibovitz et al., 1978) and wild (Gordon et al., 1993) marine turtles, and spirorchiid trematodes and their eggs caused severe lesions in multiple visceral sites in marine turtles (Gordon et al., 1998). A range of amoebiasis, cryptosporidiosis, and various helminth infections are noted (Jacobson, 2007).

Species of Bothridium and Bothriocephalus are mainly parasitic to boid snakes. Heavy infections have been reported, but the extent of infection is not investigated. A pseudophyllidean cestode, Spirometra is one of the most widely distributed parasites in snakes, which are in most cases intermediate or paratenic hosts. These cestodes release eggs from the definitive host that grow into larvae (coracidia). The larvae are are ingested by a copepod, and develop into procercoids. Second intermediate host (such as amphibian, reptile, or mammal) ingest the procercoids that develop into plerocercoids, which are known as spargana. These are distributed throughout the body. Spargana may result in soft swellings of the body surfaces. Inside the tissues, they can cause edema and hemorrhage. Many cestodes of the families Ochetosomatidae (Dasymetra, Lechriorchis, Zeugorchis, Ochestosoma) and Plagiorchiidae (Stomatrema, Styphlodora) are commonly present in the oral cavity, pulmonary system and upper esophagus of snakes. They are collectively called the renifers (Jacobson, 2007). Many species of Hexametra are reported from lizards and snakes in Africa and Southeast Asia (Sprent, 1978).

Roundworm infections are prevalent in wild snakes, and pathologic lesions are usually associated. Third-stage larvae of Polydelphis quadrangularis is known to cause gastric ulceration in Neotropical rattlesnake Crotalus durissus terrificus, particularly if they are less than 173 days of age (Araujo, 1971). Pythons are commonly infected with different species of nematodes, where adults lodged in the gastric mucosa and larvae migrate through visceral tissues creating mechanical damage. The wandering larvae are responsible severe inflammatory responses. A Papuan python (Apodora papuana [formerly Liasis papuanus]) held in captivity for 4 years and died after 3 weeks of anorexia was found with adhesions between the aorta and esophagus (Hamir, 1986). The aortic wall had many fibrous nodules, the endothelial surface was roughened, and there were numerous aneurysms throughout the aorta and the peritoneum of the coelomic cavity. One nematode was identified as Ophidascaris papuanus; of which the adults were found in the intestine. A bronchopneumonia and a large area of necrosis of one lung was also noted. Other ascarids observed by Sprent (1963; 1970a, 1970b) in pythons include Ophidascaris moreliae from the carpet python (Morelia spilota variegata), Polydelphis anoura from carpet pythons, scrub pythons (Morelia amethistina), and the woma python (Aspidites ramsayi), and Amplicaecum robertsi in the carpet python, where encapsulated larvae 


\section{ATLANTIS
PRESS}

Figure 1: Cestode recovered from intestinal lining of $O$. hannah.

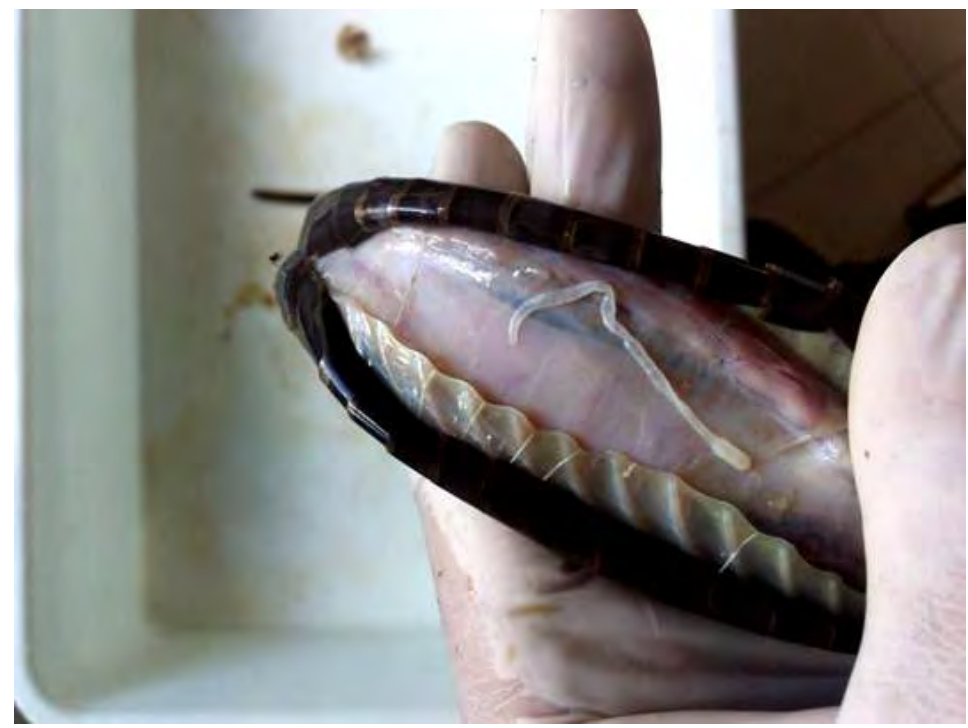

Figure 2: Cystacanth of Acanthocephala recovered from intestinal lining of $O$. hannah.

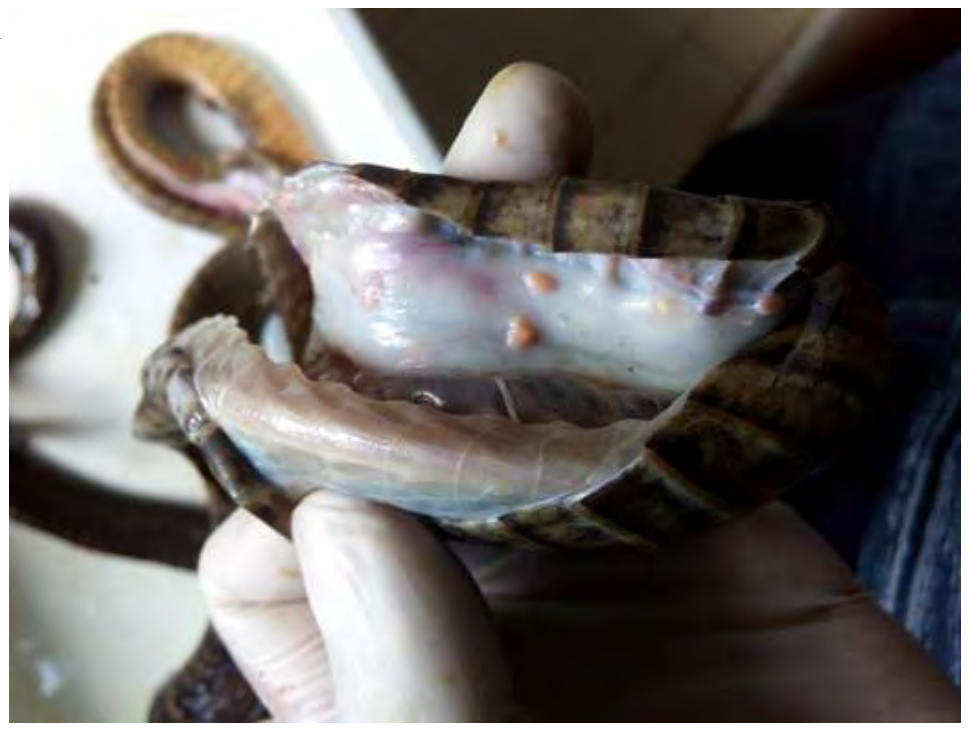

Figure 3: Cystacanth of Acanthocephala recovered from intestinal lining of $O$. hannah.

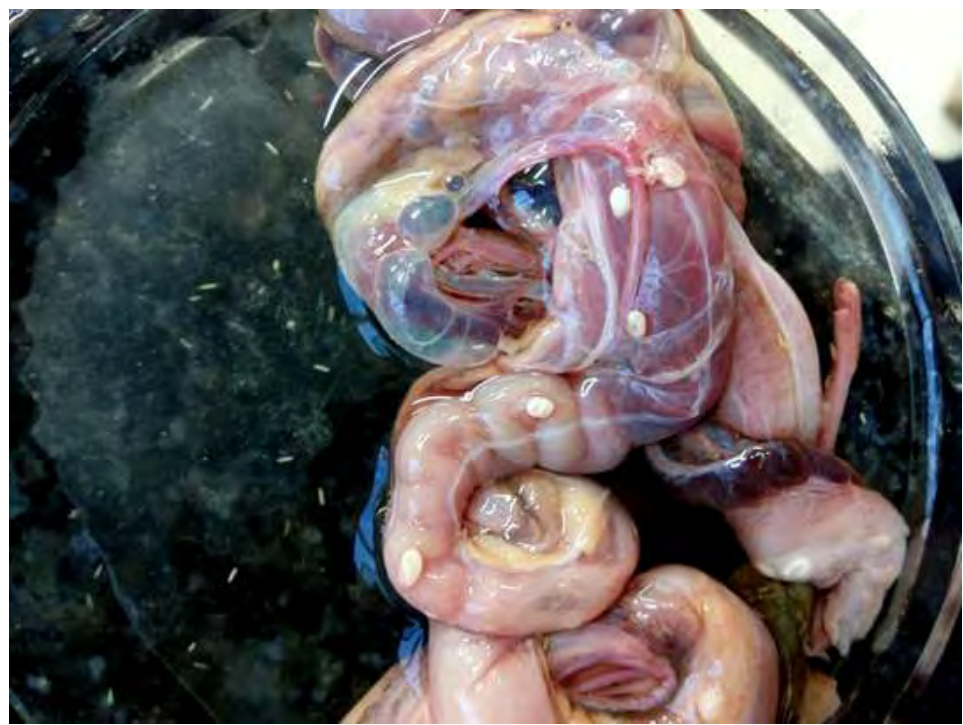




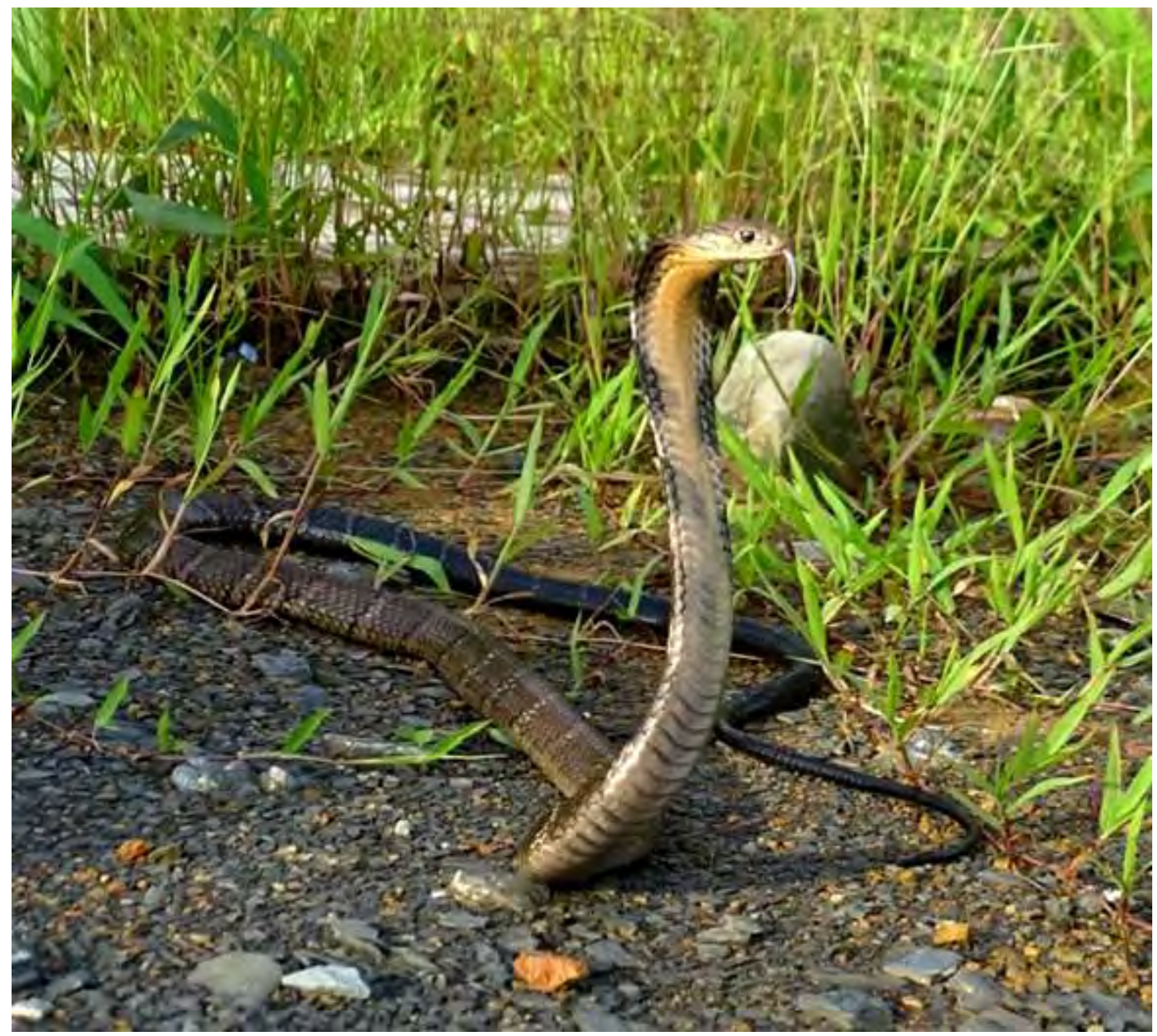

Figure 4: Ophiophagus hannah (host species of Capillaria sp., Ophidascaris sp., Metacestode of Taenia sp., and Acanthocephala.

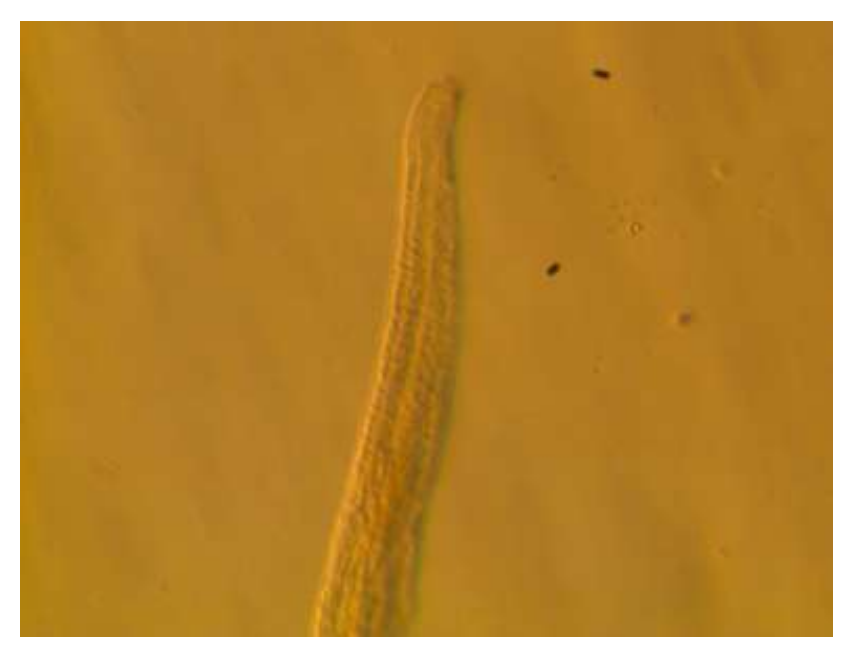

Figure 5: Head portion of female Capillaria sp.

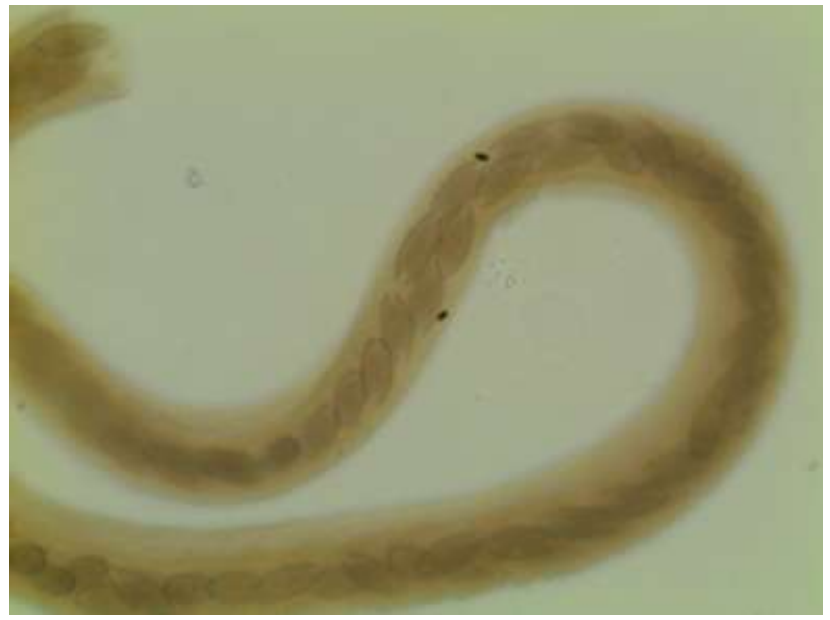

Figure 6: Mid-portion of gravid female Capillaria sp. 


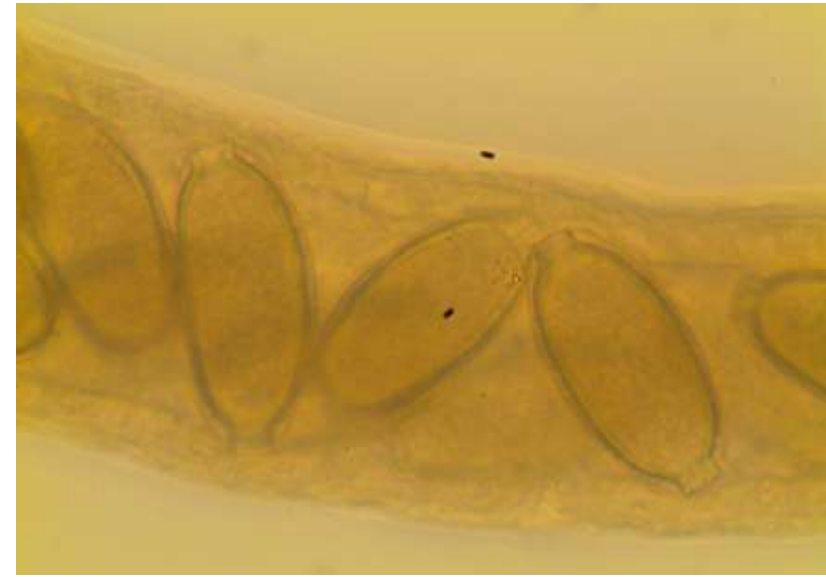

Figure 7: Female Capillaria sp. with magnified eggs with polar plug in uterus (single row).

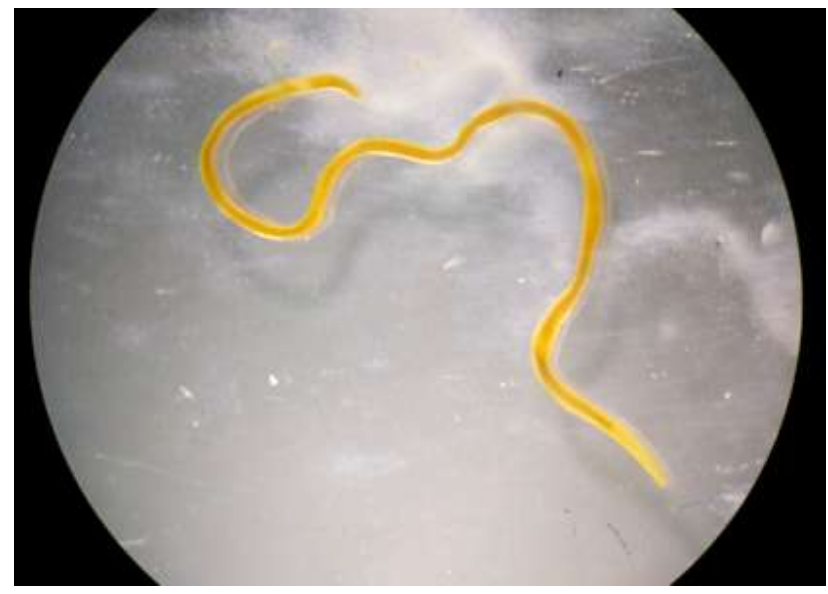

Figure 9: Male Ophidascaris sp.

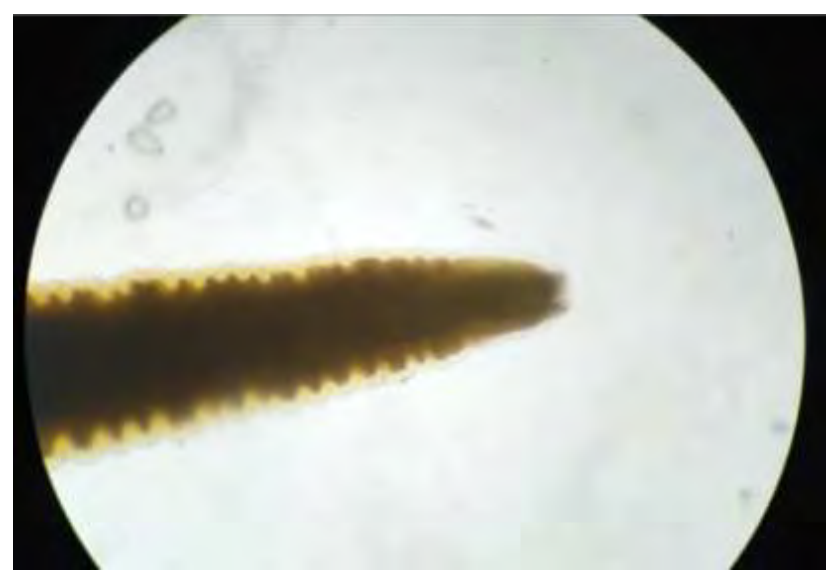

Figure 11: Anterior end of female Ophidascaris sp.

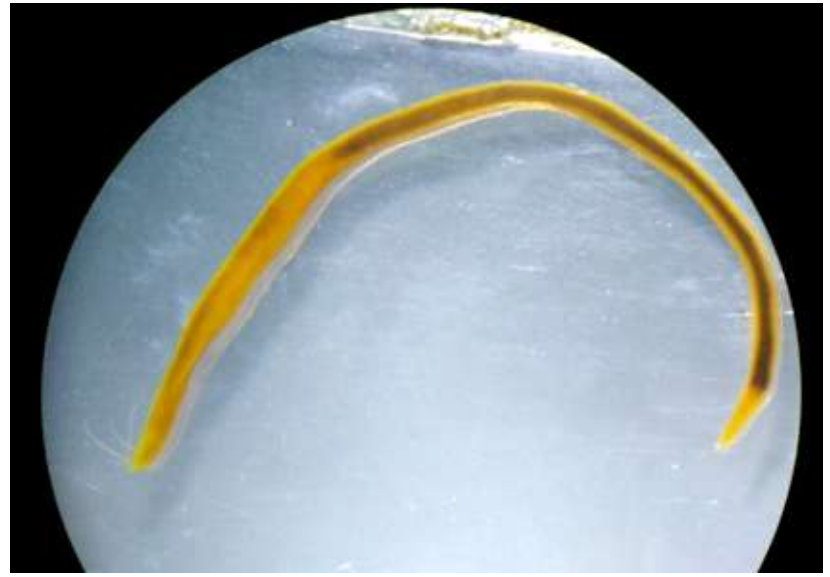

Figure 8: Female Ophidascaris sp.

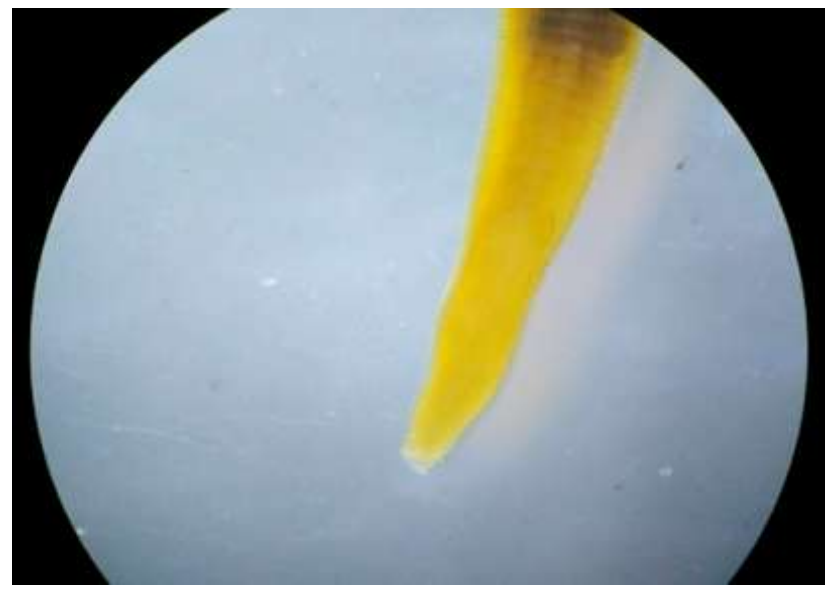

Figure 10: Anterior end of male Ophidascaris sp.

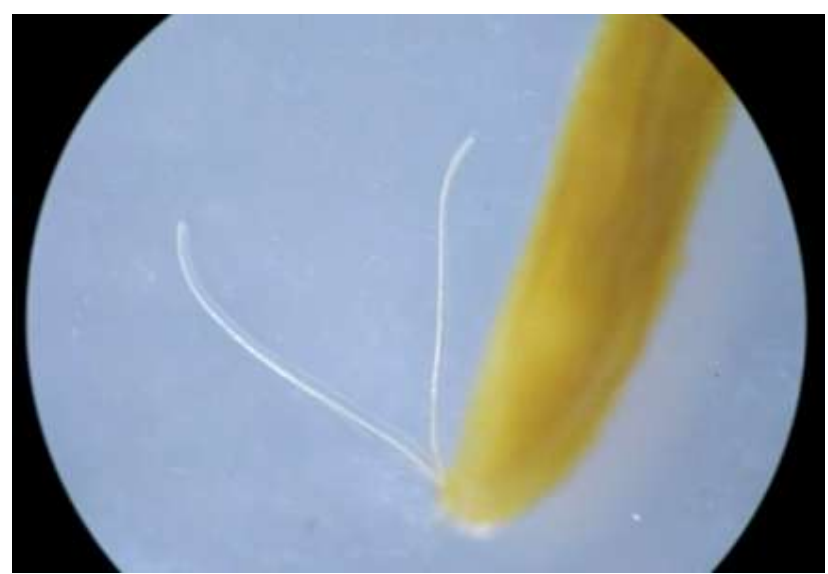

Figure 12: Posterior end of male Ophidascaris sp. 

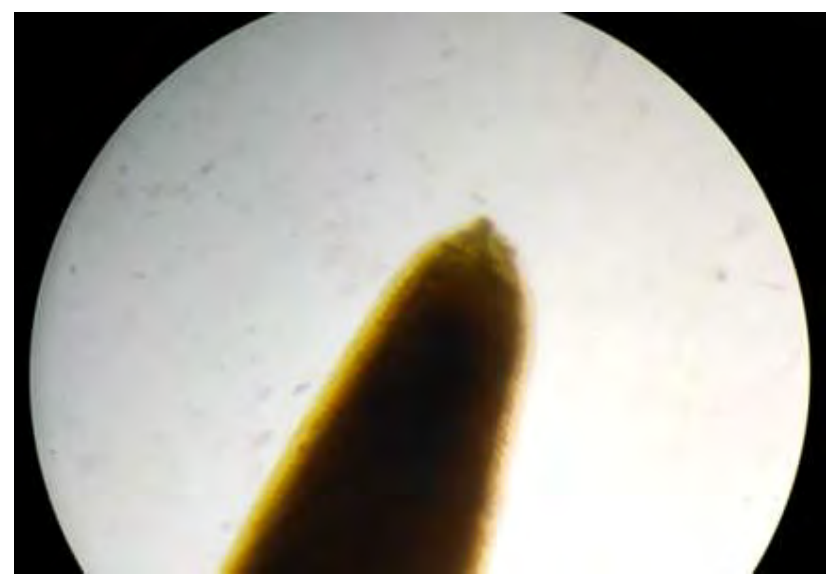

Figure 13: Posterior end of female Ophidascaris sp.
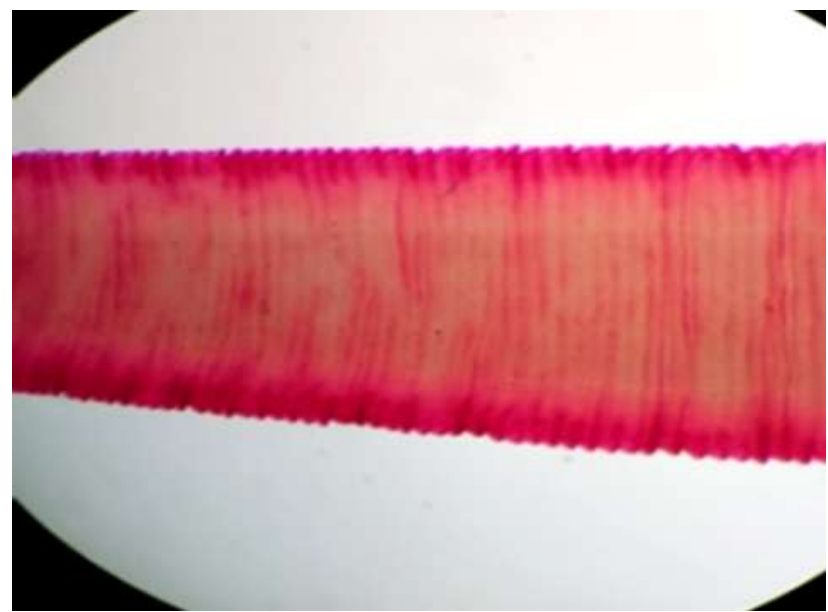

Figure 14 (b): Metacestode of Taenia sp. Mid-section showing segments.

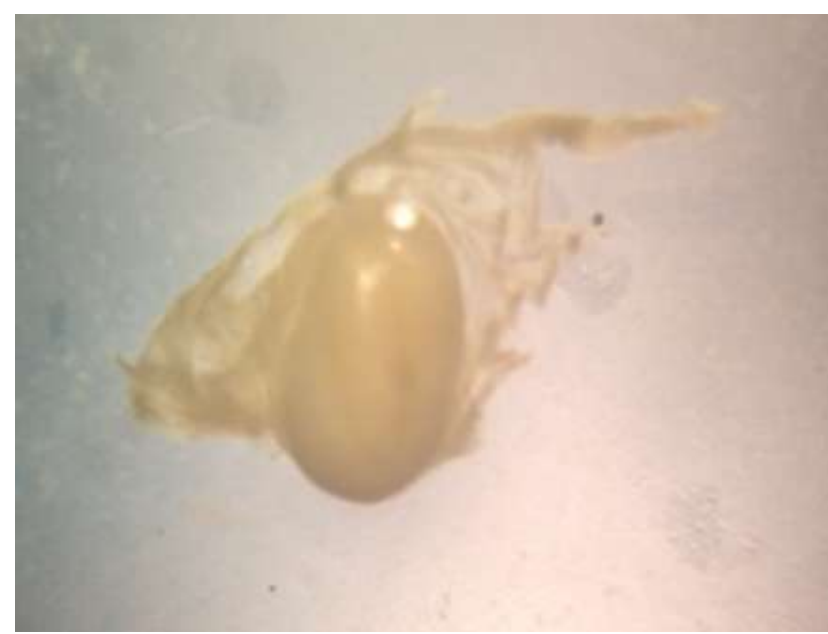

Figure 15: Cystacanth of Acanthocephala.

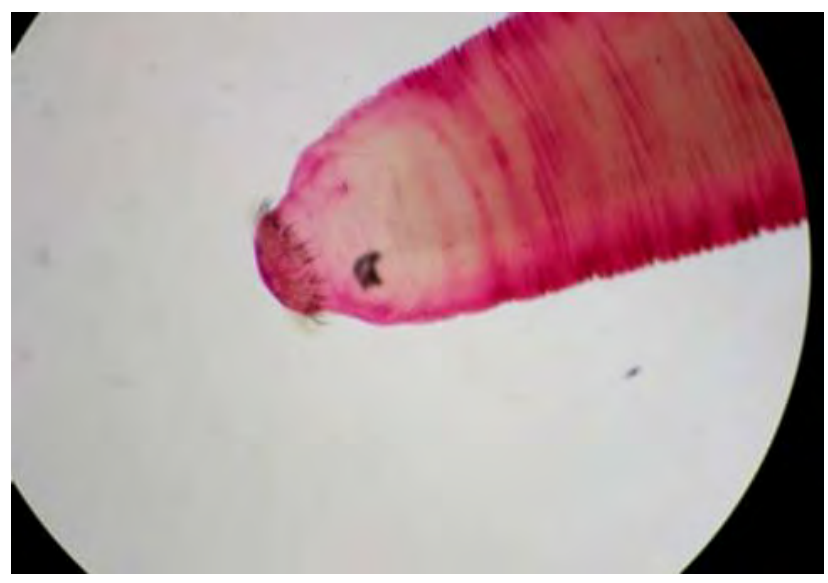

Figure 14 (a): Metacestode of Taenia sp. Anterior end showing scolex.

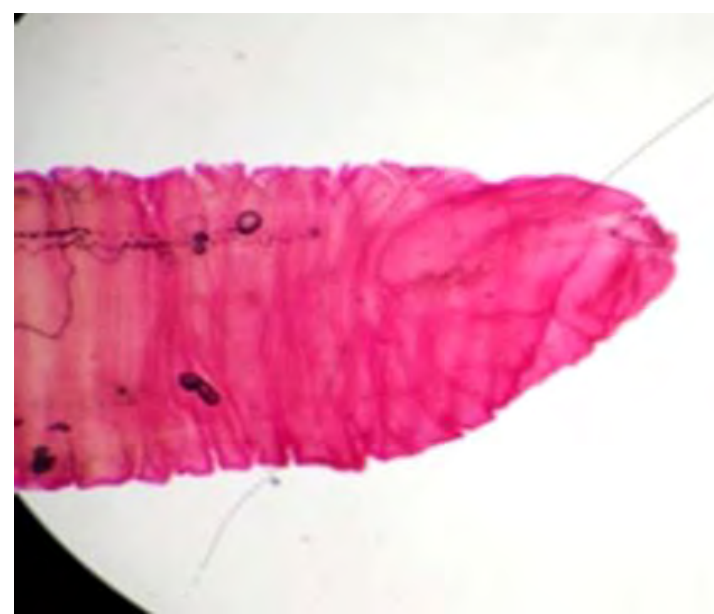

Figure 14 (c): Metacestode of Taenia sp. Posterior end showing bulb.

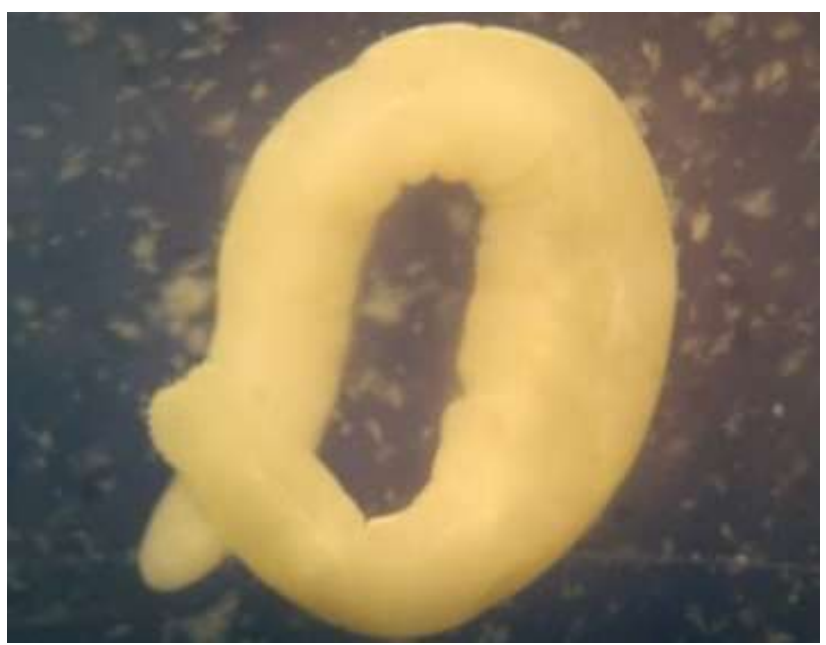

Figure 16: Acanthocephala with no pseudosegmentation. 


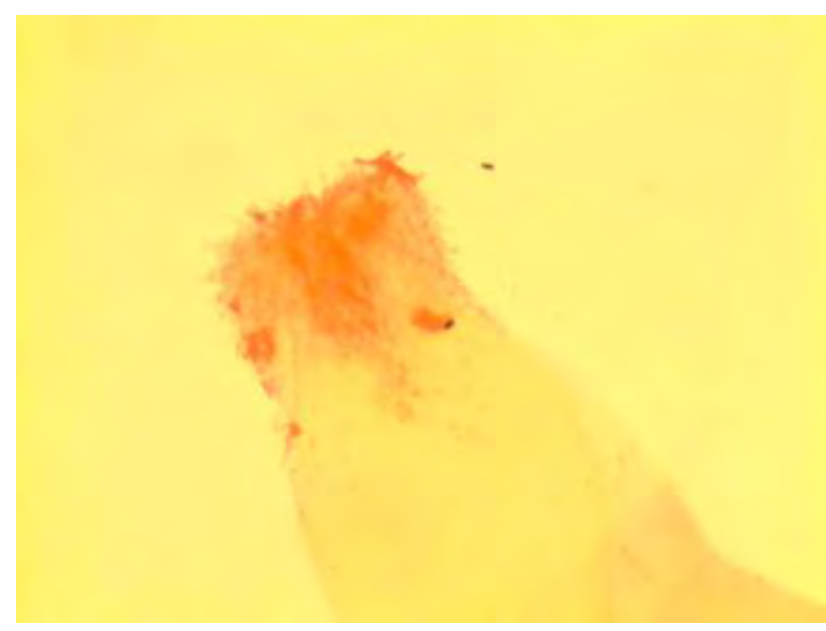

Figure 17: Anterior part of Acanthocephala with hooks.

were seen in the aorta (Sprent, 1963). Third-stage larvae of Ophidascaris moreliae were either found free or attached to the surface of the lungs (Sprent 1970a). Adults of Ophidascaris moreliae are found in the stomach and intestine (Jacobson, 2007). An adult king cobra (Ophiophagus hannah) was infected with mature Sphaerechinorhynchus serpenticola (Jacobson, 2007). Cystacanths of the acanthocephalan Macracanthorhynchus ingens were identified in several species of snakes in Louisiana (Elkins and Nickol, 1983). Cystacanths of Centrorhynchus spinosus and Macracanthorhynchus ingens were identified in eastern indigo snakes in Florida (Foster et al., 2000)

\section{REFERENCES}

Araujo, P., (1971). Considerations sur la deuxieme mue des larves d'Ascarides parasites Vol. II. Filarioidea, Dioctophymoidea and Trichinelloidea. Taylor and Francis, Ltd., London.

Daniel, J.C. (2002). The Book of Indian Reptiles and Amphibians. Oxford University Press, Bombay Natural History Society.

Elkins, C.A., Nickol, B.B. (1983). The epizootiology of Macracanthorhynchus ingens in Louisiana. J. Parasitol. 69: 951-956.

Foster, G.W., Moler, P.E., Kinsella, J.M., Terrell, S.P., Forrester, D.J. (2000). Parasites of eastern indigo snakes from Florida, USA. Comp. Parasitol. 67:124-128.

Gordon, A.N., Kelly, W.R., Cribb, T.H. (1998). Lesions caused by cardiovascular flukes (Digenea: Spirorchidae) in stranded green turtles (Chelonia mydas). Vet. Pathol. 35: 21-30.

Gordon, A.N., Kelly, W.R., Lester, J.G. (1993). Epizootic mortality of free-living green turtles, Chelonia mydas, due to coccidiosis. J. Wildl. Dis. 29: 490-494.

Hamir, A.N. (1986). Aortitis caused by Ophidascaris papuanus in a python. J. Amer. Vet. Med. Assoc. 189:1129-
1130.

Hedges, S.B., Poling, L.L. (1999). A molecular phylogeny of reptiles. Science. 283:998-2001.

Jacobson, E.R. (2007). Infectious Diseases and Pathology of Reptiles. CRC Press, Tailor and Francis Group, Boca Raton, FLorida.

Khalil, L.F., Jones, A., Bray, R.A. (1994). Keys to the Cestode Parasites of Vertebrates. Commonwealth Agricultural Bureaux, England.

Lalbiakzuala, Lalremsanga, H.T. (2017). Geographic distribution: India. Mizoram: Lycodon fasciatus. Herpetological Review. 48 (1): 131.

Lalremsanga, H.T., Lalronunga, S. (2017). Indian snakes (Zoram Rul Chanchin). MISTIC Mizoram, BIOCONE, Guwahati, Bhabani.

Leibovitz, L., Rebell, G., Boucher, G.C. (1978). Caryospora cheloniae sp.n.: A coccidial pathogen of mariculturereared green sea turtles (Chelonia mydas mydas). J Wildl Dis 14:269-275.

Li, L., Zhao, W.T., Chen, H.X., Guo, W.N., Zhang, L.P. (2016). Morphological study of Ophidascaris excavata Hsu \& Hoeppli, 1931 (Ascaridida: Ascarididae) from Gloydius brevicaudus (Stejneger) (Reptilia: Viperidae). Syst. Parasitol. 93: 69-75.

Noryoska, M. R., Sokół, R. (2015). Internal parasites of reptiles. Annals of parasitology. 61(2), 115-117.

Panizzutti, M.H.M., Santosi, L.C.d., Vicente, J.J., Pereira, L.C.M., Pinto, R.M. (2003). Ophidascaris durissus sp. nov. (Nematoda Ascarididae) parasitizing Crotalus durissus Linnaeus (Ophidia, Viperidae) in Brazil. Rev. Bras. Zool.20: 1.

Radhakrishnan, S., Kurup, S.P., Bannerjee, P.S. (2009). Endoparasitism in captive wild-caught snakes indigenous to Kerala, India. Zoo Biology. 28: 253-258.

Rieppel, O., Reisz, R.R. (1999). The origin and early evolution of turtles. Ann. Rev. Ecol. Syst. 30: 1-22.

Schall, J.J. (1996). Malarial Parasites of Lizards: Diversity and Ecology.

Schneller, P., Pantchev, N. (2008). Parasitology in Snakes, Lizards and Chelonians (A husbandry Guide). Chimaira, Frankfurt am Main.

Sprent, J.F.A. (1963). The life history and development of Amplicaecum robertsi, an ascaridoid nematode of the carpet python Morelia spilotes variegatus. Parasitology. 53:321-337.

Sprent, J.F.A. (1970a). Studies on ascaridoid nematodes in pythons: The life-history and development of Ophidascaris moreliae in Australian pythons. Parasitology. 60:97-122.

Sprent, J.F.A. (1970b). Studies on ascaridoid nematodes in pythons: the life-history and development of Polydelphis anoura in Australian pythons. Parasitology. 60:375-397.

Sprent, J.F.A. (1978). A scaridoid nematodes of amphibians and reptiles: Polydelphis, Travassosascaris n. g., and Hexametra. J. Helminthol. 52:355-384.

Uetz, P. (2016). The Reptile Database. http://www.reptile 
-database.org.

Vivek, S. (2014). Checklist of snakes of India. vivek@indiansnakes.org.

Wang, F., Li, W., Hua, L., Gong, S., Xiao, J., Hou, F., Ge, W., Yang, G. (2014). Spirometra (Pseudophyllidea, Diphyllobothriidae) Severely Infecting Wild-Caught Snakes from Food Markets in Guangzhou and Shenzhen, Guangdong, China: Implications for Public Health. The Scientific World Journal. 874014: 5.

Wolf, D., Vrhovec, M.G., Failing, K., Rossier, C., Hermosilla, C., Pantchev, N. (2014). Diagnosis of gastrointestinal parasites in reptiles: comparison of two coprological methods. Acta Veterinaria Scandinavica.
56:44.

Yamaguti, S. (1959). Systema Helminthum. Vol. II- Cestodes of Vertebrates. Interscience Publishers Inc. New York.

Yamaguti, S. (1959). Systema Helminthum. Vol. IIINematodes of Vertebrates. Interscience Publishers Inc. New York.

Yamaguti, S. (1961). Systema Helminthum. Vol.V- Acanthocephala of Vertebrates. Interscience Publishers Inc. New York.

Zardoya, R., Meyer, A. (1998). Complete mitochondrial genome suggests diapsid affinities of turtles. Proc. Natl. Acad. Sci. USA. 95:14226-14231. 